\title{
Espaço escolar e violência no cotidiano vivido por crianças e adolescentes em Ponta Grossa-PR, 2005 - 2007
}

\section{Achool space and violence in everyday context experienced by children and adolescents in Ponta Grossa-PR, 2005 - 2007}

\author{
Adriane Iaroczinski \\ Universidade Estadual de Ponta Grossa \\ Joseli Maria Silva \\ Universidade Estadual de Ponta Grossa
}

\begin{abstract}
Resumo: Este artigo tem por objetivo compreender o papel do espaço escolar nas relações sociais cotidianas vividas por crianças e adolescentes de instituições de ensino público em Ponta Grossa. Neste contexto encontra-se a violência escolar, grave problema enfrentado pelas escolas atualmente, existindo diferenças na distribuição espacial das ocorrências e no perfil dos atos violentos cometidos pelo grupo social infanto-juvenil. Para cumprir o propósito do trabalho de investigação foram levantados os dados da Polícia Militar do Programa da Patrulha Escolar instituído em 2004 e realizadas entrevistas exploratórias com policiais e dirigentes das escolas. A partir dos boletins de ocorrências foi construído o perfil da violência e as características das pessoas envolvidas. Há evidências de que as ocorrências são mais freqüentes em escolas que congregam alunos da faixa etária da adolescência e que possuem clientelas de áreas urbanas bastante diversificadas, aumentando a possibilidade de conflitos. Enfim, o espaço escolar apresenta sua complexidade na medida em que compõem e é composto pela sociedade e ao mesmo tempo possui regras próprias, além disso, possibilita também produzir a resistência contra o aumento da violência urbana.
\end{abstract}

Palavras-chave: Espaço escolar. Violência infanto-juvenil. Ponta Grossa.

\begin{abstract}
This article aims to understand the role of school everyday social relationships experienced by children and adolescents in institutions of public education in Ponta Grossa. In this context is the school violence, serious problem faced by schools today, there are differences in spatial distribution of events and the profile of violent acts committed by infant-adolescent social group. To achieve the aim of the research work were raised to data from the Program of Military Police Patrol School established in 2004 and held exploratory interviews with police and leaders of schools. From the newsletter of events was constructed the profile of violence and characteristics of those involved. There is evidence that such occurrences are more frequent in schools that bring together students from the age of adolescence and that customers have very diverse, urban areas, increasing the possibility of conflicts. Finally, the school presents its complexity in that component and is made by the company and at the same time has its own rules, moreover, allows also produce resistance to the rise in urban violence.
\end{abstract}

Keywords: School space. Infant-adolescent violence. Ponta Grossa.

\footnotetext{
${ }^{1}$ Agradecimentos especiais ao Batalhão da Polícia Militar do Paraná de Ponta Grossa, instituição que possibilitou o acesso às fontes de pesquisa e auxiliou na discussão dos dados obtidos.
} 


\section{INTRODUÇÃO}

A escola é uma instituição que possibilita, em princípio, o acesso à aprendizagem e socialização dos indivíduos de forma democrática, promovendo condições para as pessoas viverem melhor e integrar-se na sociedade. No entanto, a escola vem se tornando um espaço de conflitos e, portanto, se descaracteriza como um espaço de atração, interesse e prazer para crianças e adolescentes.

A teoria crítica educacional afirma que a escola evoluiu ao longo de sua história, mas ainda se mantêm a concepção filosófica da educação com o principal objetivo de formar cidadãos para atender ao mercado capitalista, deixando a desejar uma formação mais humanista, livre, autônoma e democrática.

A escola é parte integrante do contexto histórico, social e espacial a que pertence e participa do conjunto dos fenômenos que compõem a realidade sócio-espacial. Entender a escola como um elemento que se constrói juntamente com as vidas de homens e mulheres é promover a concepção de um espaço escolar que pode ser transformado continuamente por elementos constituintes da sociedade.

Quando a sociedade passa por transformações sociais, o espaço escolar também se transforma e assim, a violência urbana crescente passa a fazer parte do cotidiano escolar e a escola é parte dos cenários de atos violentos advindos de um espaço social desestruturado e fragilizado.

A violência escolar está entre um dos mais complexos desafios enfrentados pelas instituições de ensino. Com o propósito de compreender o espaço escolar e sua relação com a violência infanto-juvenil em Ponta Grossa foi realizado um levantamento dos boletins de ocorrências no $1^{\circ}$ Batalhão da Policial Militar do Paraná - Programa da Patrulha Escolar no período de 2005 a 2007. Na seqüência, foram feitas entrevistas exploratórias com os policiais integrantes do referido programa e com os representantes das instituições de ensino público da cidade que apresentaram o maior número de registros de ocorrências de violência escolar. As entrevistas contemplaram a visão dos depoentes sobre o fenômeno da violência escolar como causas, conseqüências, dificuldades, desempenhos e avaliações.

\section{ESPAÇO ESCOLAR COMO INSTITUÍDO E INSTITUINTE DAS RELAÇÕES SOCIAIS COTIDIANAS DAS CRIANÇAS E ADOLESCENTES.}

O espaço escolar compõe a cidade, assim como por ela é composto. São escalas de análise que se inter-relacionam e produzem simultaneamente a sociedade. Segundo Soja (1993, p.101), “o espaço socialmente produzido é uma estrutura criada, comparável a outras estruturas sociais resultantes da transformação de determinadas condições inerentes ao estar vivo, exatamente da mesma maneira que a história humana representa transformação social do tempo". Santos (1996) discute o conceito de formação sócio-espacial, considerando que a sociedade só se torna concreta através do espaço, de um sistema de objetos e ações. Para análise do espaço, o autor cria as seguintes categorias de análise: forma, função, estrutura e processo. No caso da análise do espaço escolar, a forma é o aspecto físico da instituição escolar. A função é o papel que a sociedade atribui à escola 
e possui uma relação não linear das relações que se constroem no cotidiano escolar. A estrutura constitui-se na lógica das relações sociais que dá sentido a instituição escolar e o processo é o movimento dessas mesmas relações, envolvendo a simultaneidade de todas as categorias.

Assim, o espaço escolar, enquanto uma criação social, se faz de relações e funções próprias definidas socialmente, que possibilita e viabiliza funções específicas da ordem estatal e contraditoriamente constrói uma função limitada a vida cotidiana. Diante dessa concepção o espaço escolar pode ser compreendido como um ambiente que também é produzido e construído socialmente.

Segundo Alves e Pretto (1999 p. 29) "a palavra escola em grego significa o lugar do ócio e surge, na Idade Média, para atender a demanda de uma nova classe social que não precisava trabalhar para garantir a sua sobrevivência, mas que necessitava ocupar o seu tempo ocioso de forma nobre e digna". Segundo essa abordagem, ao longo da história a escola se tornou um lugar de necessidades e obrigações na obtenção de informação e capacitação para o mercado de trabalho. Estes autores argumentam que a figura da escola na vida social de crianças e adolescentes tem sido um lugar de cumprimento de obrigações conforme o interesse da sociedade e, sendo assim, passa a ser desprazerosa e angustiante, levando à conflitos.

As escolas públicas se caracterizam por uma estrutura determinada pela esfera do Estado, o qual visa o cumprimento de suas leis e normas vigentes por intermédio de órgãos centrais responsáveis pela regulamentação, fiscalização, administração e organi- zação. Sendo assim, o espaço escolar se diferencia do espaço no qual está inserido, pois, no seu interior existem regras de funcionamento pautadas numa proposta educacional que segue as linhas estruturais do poder regulador. Adicionalmente, a escola é também um espaço de lutas e os conflitos produzidos podem ser fontes de transformação social.

Entender a escola como um espaço social é um componente básico que contribui significativamente para a prática do papel da escola contemporânea. A sociedade atual exige para o mercado de trabalho mão-de-obra qualificada para suprir as necessidades de diversos setores de sua economia. Portanto, cabe à escola um papel importante de qualificar os sujeitos. Essa perspectiva tecnicista, a qual visa uma educação como instrumento do capital, apresenta versões diferentes que ajudam a aumentar as diferenças sociais pois, se a escola aparece como uma instituição única, os sistemas de ensino possuem características que levam à diferentes resultados "entre a formação científica e humanista para as elites e o treinamento técnico voltado para o trabalho destinado às classes populares". (MOCHCOVITCH, 1990, p. 49).

A oposição à noção tecnicista da escola se faz na compreensão de que a escola é parte integrante da dinâmica sócio-espacial e organizadora das consciências. De acordo com Gandin (1997, p. 9) "a escola é um espaço como outros (partido, sindicato, comunidade de base) no acontecimento da luta social, nela também pode produzir-se e/ou analisar-se o conflito que é a fonte de transformação".

O sentido da escola, segundo Saviani (1991), deve superar o papel de apenas servir como instrumento de dominação 
que acaba por ser responsável pela marginalização de parte da sociedade e argumenta que a teoria crítica tem um papel fundamental na luta por construir uma escola como fator de superação da dominação. Concretiza sua idéia defendendo uma escola que possibilite e forneça escolhas ao sujeito de forma livre e consciente de seu tempo, espaço e sociedade.

O espaço escolar é mais do que um local no qual se educam as crianças e adolescentes. É no espaço escolar que se vive a vida repleta de expectativas, frustrações, afetos, medos, desejos, amores e é ainda através da vivência escolar que ocorrem os encontros de diferentes culturas e valores que cada sujeito traz de seus espaços de moradia. Nesse sentido, o espaço escolar tornase complexo porque, embora seja parte integrante do espaço da cidade, tem algumas peculiaridades que o torna particular. É no jogo entre as escalas do espaço urbano e do espaço escolar que se constrói uma dinâmica específica de relações sociais, pois, conforme Corrêa (1997, p. 44) “o espaço geográfico é multidimensional" e é esta a característica que modela os conflitos que ocorrem na vivência escolar.

O espaço escolar compreendido por esta pesquisa é instituinte e instituidor das sociabilidades cotidianas que envolvem inúmeras características também presentes na sociedade ambiente. Assim, uma sociedade marcada por conflitos, desigualdades e violência institui uma escola com tais características. A escola pode ser vítima, mas também promotora da violência e esta ambigüidade está presente em sua existência institucional.

São muitas as facetas da violência que podem ser vividas nos espaços escolares. Abramovay (2002) dife- rencia a violência a partir de duas formas distintas, a física e a simbólica. A violência física é caracterizada por agressões, roubos, assaltos etc. A violência simbólica é exercida pelo abuso do poder mediante o uso de símbolos de autoridade, por agressões verbais e por atos institucionais que produzem marginalização e discriminação.

A escola é componente da violência presente na sociedade, conforme aponta Fernández (2005). Contudo, a escola oferece, pelas suas particulatidades, algumas fronteiras que a violência não conseguiu conquistar plenamente e nesse sentido, a escola pode ser compreendida também como um espaço de resistência e transformação social.

O espaço escolar, portanto, apresenta-se altamente complexo e contraditório. Promove a violência em seu papel intrínseco à cidade cada vez mais fragmentada, segregada, injusta e insegura. Mas, paradoxalmente, pode ser o espaço da geração de novas perspectivas de enfrentamento à desagregação social e construção de dinâmicas sociais mais justas e solidárias. Compreender os conflitos sociais que emergem do espaço escolar é parte desta construção.

\section{AS CARACTERÍSTICAS DA VIOLÊNCIA INFANTO- JUVENIL $^{2}$ NO ESPAÇO ESCOLAR EM PONTA GROSSA-PR.}

O espaço escolar e a violência a ele associada está relacionado com vários e heterogêneos elementos. A localização da escola pode potencializar as ações violentas quando é próxima de bares que vendem bebidas alcoólicas,

\footnotetext{
${ }^{2}$ De acordo com o Estatuto da Criança e do Adolescente no seu artigo $2^{\circ}$, do título I das Disposições preliminares, considera criança, a pessoa até doze anos de idade incompletos e adolescentes aquela entre doze e dezoito anos de idade.
} 
praças que possibilitam a permanência de grupos de jovens rivais, ginásios de esportes onde ocorrem competições que deflagram agressões entre torcidas adversárias, assim como a presença de pontos de venda de drogas. Desequilíbrios psicológicos individuais e de ordem familiar também são relevantes. A conjugação desses fatores constitui maior possibilidade de constituir um espaço escolar em que se desenvolvam atos violentos que, cada vez mais, foge ao controle da comunidade escolar (alunos, professores, funcionários e pais). Assim, o governo do estado do Paraná criou um programa especial para minimizar os índices de violência presentes nas escolas paranaenses.

Foi criado em 2004 o Programa da Patrulha Escolar inserido na estrutura da Polícia Militar. O programa foi efetivado de forma gradativa, seguindo um planejamento criterioso. $\mathrm{Na}$ primeira etapa, realizou-se o mapeamento, monitoramento e coleta das informações de cada estabelecimento de ensino verificando e identificando os problemas relativos à fragilidade do controle de acesso das pessoas ao espaço escolar como as condições dos muros, alarmes, entrada e saída dos alunos e presença de terrenos baldios em seu entorno imediato. Na segunda etapa, foram realizadas dinâmicas com a comunidade escolar, levantando os principais problemas existentes no ambiente intra-escolar e arredores. $\mathrm{Na}$ terceira etapa, foi desenvolvido o plano de ação e providências a serem implementadas e na quarta etapa, realizou-se a execução do plano de ação, palestras com pais, alunos, funcionários, direção e professores. Os temas relevantes estavam relacionados com o Estatuto da Criança e do Adolescente (ECA), orientação de segurança, desenvol- vimento da cidadania e auto-estima, prevenção ao uso de drogas, aspectos pedagógicos, treinamentos dos funcionários e regras de trânsito. Na quinta e última etapa, foi elaborado o plano de segurança que contempla o patrulhamento diferenciado e a interação com a comunidade, já que os policiais têm a função de aconselhar os alunos, mediar conflitos e assessorar os diretores das escolas.

A cidade é dividida em áreas monitoradas por equipes de policiais que realizam patrulhamentos rotineiros no entorno das escolas e quando há necessidade, desenvolvem ações em seu interior. As ações no interior das escolas foram mais freqüentes durante a fase de averiguação e reconhecimento dos indicadores de violência presentes nas escolas, chamadas de operações de revistas preventivas. Consiste em realizar uma operação surpresa durante a qual os alunos e seus pertences são revistados, em geral, nas salas de aula ou dependências internas.

As regiões, Nova Rússia, Oficinas, Centro e Uvaranas são monitoradas por dezesseis policiais que compõem o programa desenvolvido pela Polícia Militar e realizam intervenções em um determinado número de escolas e seu entorno como pode ser observado na figura 1. 


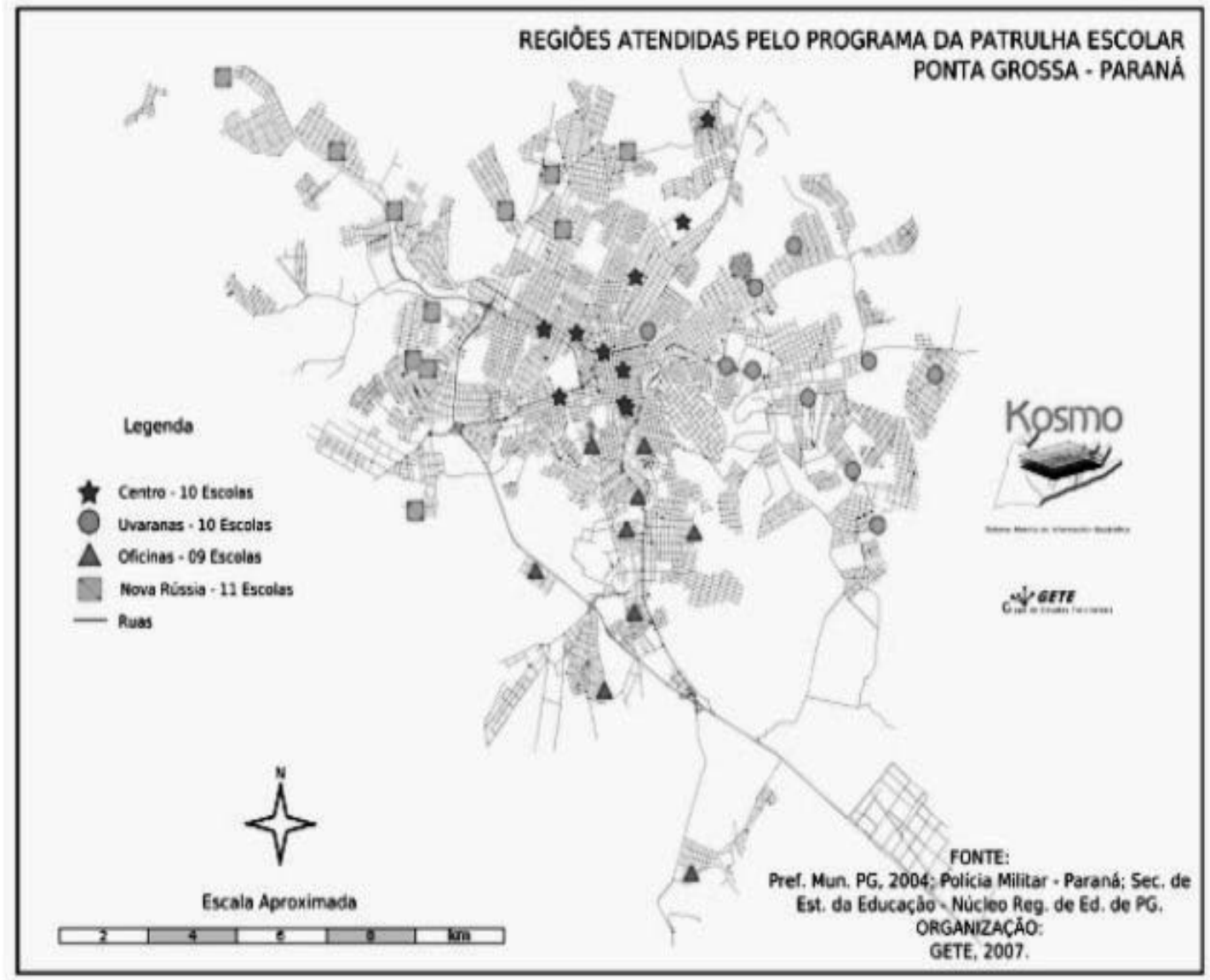

Figura 1: Regiões atendidas pelo Programa da Patrulha Escolar.

Fonte: Prefeitura Municipal de Ponta Grossa, 2004; Polícia Militar do Paraná; Secretária Estadual de Educação - Núcleo Regional de Educação de Ponta Grossa.

Org. GETE - Grupo de Estudos Territoriais, 2007.

Entre 2005 e 2006 foram realizadas revistas preventivas pela Polícia Militar do Paraná através do Programa Patrulha Escolar nas quarenta e quatro escolas públicas da cidade de Ponta Grossa-PR. O gráfico 1 evidencia as ocorrências verificadas neste primeiro período de ação da patrulha escolar, onde foram apreendidos produtos tóxicos, armas de fogo e armas brancas.
Gráfico 1: Resultado das revistas preventivas nas 44 escolas em Ponta Grossa-PR no ano de 2005.

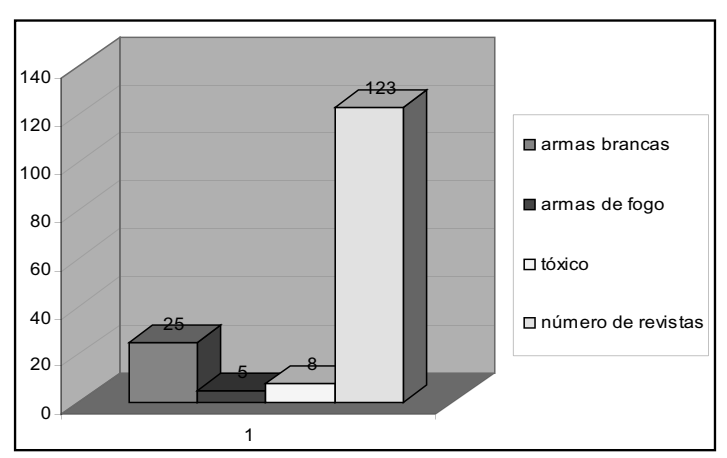

Fonte: Polícia Militar do Paraná - Programa Patrulha Escolar - 2005. Org. Adriane Iaroczinski. 
Quando comparados os dados dos gráficos 1 e 2, observa-se que a apreensão de produtos tóxicos desaparece no segundo ano de desenvolvimento do programa, mas é constante ainda o porte de armas de fogo e/ou armas brancas, ambos considerados atos infracionais graves. Segundo entrevistas com os policiais militares componentes do programa, os dados não levam a uma avaliação otimista sobre o desaparecimento da apreensão dos produtos tóxicos. Afirmam que as escolas ainda não estão livres das drogas e o desaparecimento dos produtos tóxicos apreendidos deve-se a dois fatores principais. Primeiro, porque as revistas realizadas de surpresa durante o ano de 2005 geraram a apreensão das mercadorias dos traficantes que, segundo eles, estão utilizando novas táticas, como a venda nos arredores da escola. Além disso, a apreensão dentro do prédio escolar declinou porque as abordagens internas também diminuíram, conforme prevê o cronograma de execução do programa. $\mathrm{Na}$ fase atual, as revistas somente são realizadas mediante o acionamento prévio por parte das instituições de ensino.

Gráfico 2: Resultado das revistas preventivas nas 44 escolas em Ponta Grossa-PR até junho de 2006.

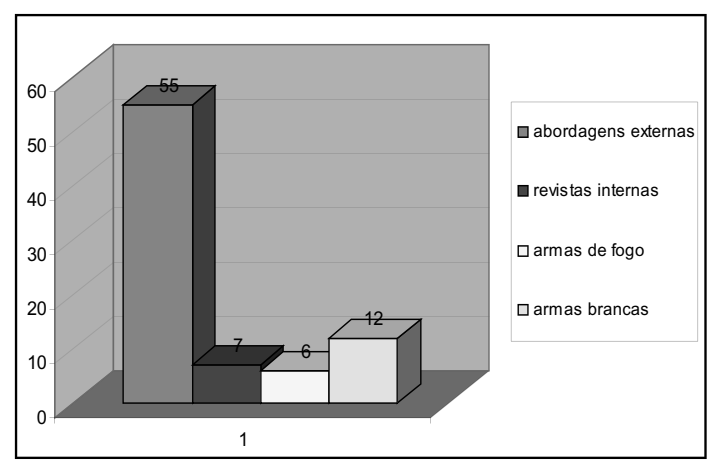

Fonte: Polícia Militar do Paraná - Programa Patrulha Escolar - 2006. Org. Adriane Iaroczinski.
Do levantamento documental realizado no $1^{\circ}$ Batalhão da Polícia Militar do Paraná, foram analisados 541 boletins de ocorrências oriundos das ações da Patrulha Escolar, abrangendo o período de 2005 a 2007. Deste universo foram considerados 375 boletins e os demais foram desprezados. A desconsideração dos boletins para a construção dos perfis da violência deve-se ao fato de que os policiais do programa da Patrulha Escolar acabam atendendo alguma emergência que ocorre próxima à viatura que, muitas vezes, não está relacionada às escolas. Estavam presentes no universo de registros da Polícia Militar - Programa da Patrulha Escolar 38 escolas da cidade de Ponta Grossa-PR. O gráfico 3 evidencia que o número de ocorrências gera quase o dobro de pessoas envolvidas.

Gráfico 3: Total de escolas/colégios, número de ocorrências e pessoas envolvidas.

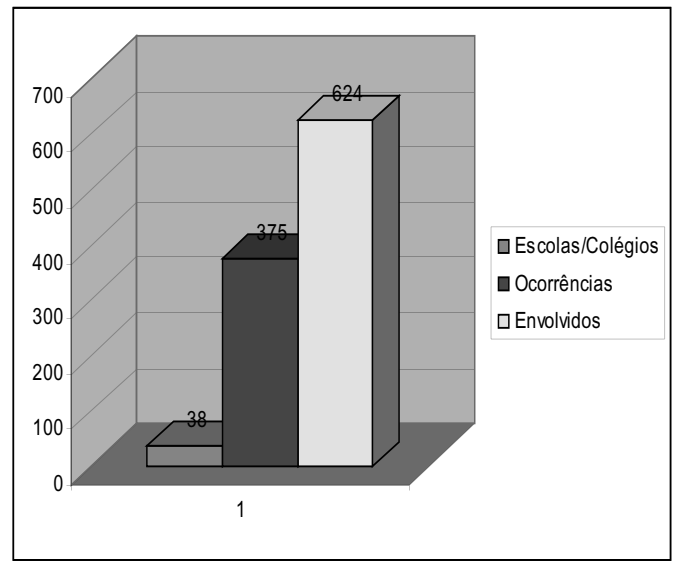

Fonte: Policia Militar do Paraná - Programa Patrulha Escolar, Ponta Grossa- PR, 2005-2007. Org. Adriane Iaroczinski

Do total de pessoas envolvidas em atos de violência no espaço escolar observa-se que o número de alunos do sexo masculino é maior do que feminino como pode ser verificado no gráfico 4. 
Gráfico 4: Total de pessoas envolvidas.

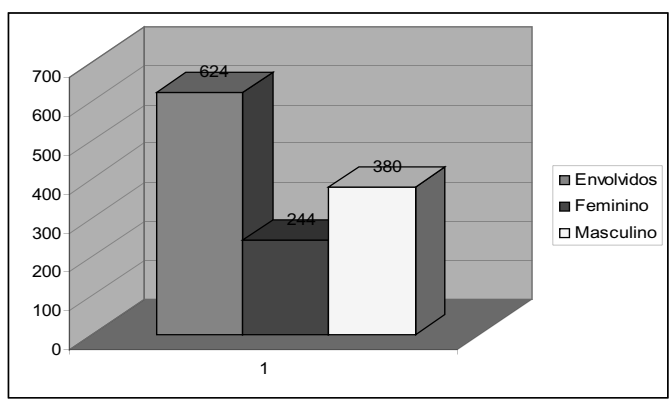

Fonte: Polícia Militar do Paraná - Programa Patrulha Escolar, Ponta Grossa- PR, 2005-2007. Org. Adriane Iaroczinski

Das trinta e oito escolas que possuem ocorrências de atos de violência registrados nos boletins da Polícia Militar destacam-se quatro: Colégio Estadual Senador Correia, Colégio Estadual Regente Feijó, Colégio Estadual Prof. João Ricardo Von Borell Du Vernay e Colégio Estadual Professor Colares como pode ser visualizado no gráfico 5.

As características do perfil dos envolvidos nas ocorrências registradas nos quatro colégios com maiores números de registros podem ser visuali- zadas na tabela 1. Os quatro colégios apresentam uma distribuição homogênea em termos de quantidade de ocorrências, com exceção do Colégio Estadual Professor Colares. Também há um equilíbrio no que diz respeito aos totais de pessoas envolvidas nos atos infracionais. Contudo, as diferenças podem ser encontradas quando comparados os universos feminino e masculino e o papel que as pessoas envolvidas desempenharam no ato violento. $\mathrm{O}$ desempenho do universo masculino é mais significativo como autor dos atos violentos e as vítimas são mais representadas pelo universo feminino excetuando o Colégio Estadual Professor Colares. Assim, a violência é um fenômeno que atinge meninos e meninas de forma diferenciada.

A natureza dos atos violentos presentes nos colégios que se destacam em número absoluto de ocorrências pode ser visualizada na tabela 2. Os atos mais comuns são vias de fato, lesão corporal, ameaça, furto simples e qualificado e danos ao patrimônio público. Os atos infracionais considerados mais graves como armas brancas e de fogo, uso e porte de substâncias tóxicas, ainda

Gráfico 5: Escolas com maior número de ocorrências registradas no período de 2005- 2007.

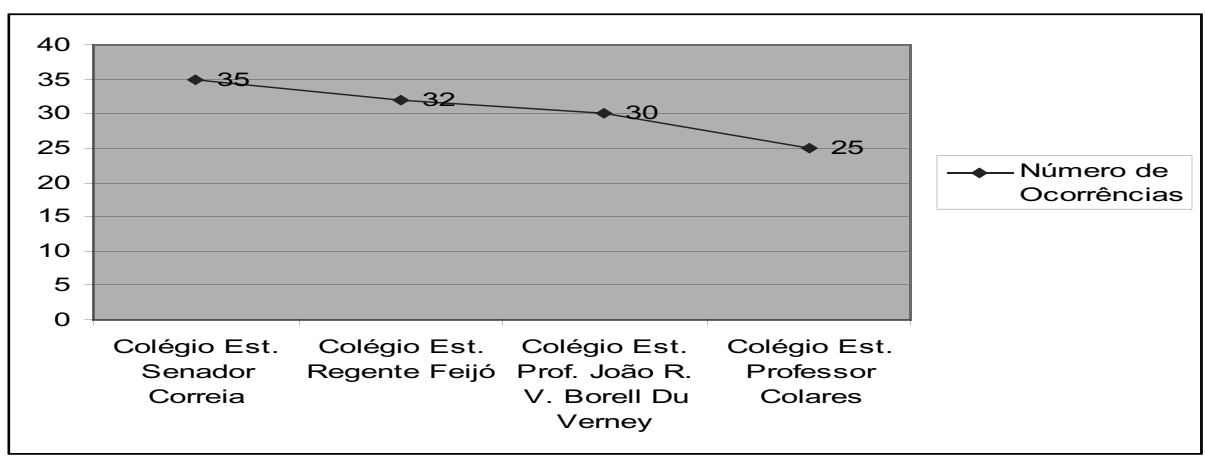

Fonte: Polícia Militar do Paraná - Programa Patrulha Escolar, Ponta Grossa- PR, 2005-2007. Org. Adriane Iaroczinski 
Tabela 1: Ocorrências por escolas e as características dos envolvidos no período de 2005-2007

\begin{tabular}{c|c|c|c|c|c|c|c|c|c|c}
\hline Escolas/Colégios & $\begin{array}{c}\mathbf{N}^{*} \\
\text { Ocorrência }\end{array}$ & $\begin{array}{c}\text { Totais } \\
\text { Envolvidos }\end{array}$ & $\mathbf{F}^{*}$ & $\mathbf{M}^{* *}$ & Autor & $\mathbf{F}^{*}$ & $\mathbf{M}^{* *}$ & Vítima & $\mathbf{F}^{*}$ & $\mathbf{M}^{* *}$ \\
\hline Colégio Est. Senador Correia & 35 & 57 & 26 & 31 & 47 & 19 & 28 & 10 & 7 & 3 \\
\hline Colégio Est. Regente Feijó & 32 & 47 & 26 & 21 & 30 & 12 & 18 & 17 & 14 & 3 \\
\hline $\begin{array}{c}\text { Colégio Est. Prof. João R. V. } \\
\text { Borell Du Vernay }\end{array}$ & 30 & 57 & 21 & 36 & 40 & 12 & 28 & 17 & 9 & 8 \\
\hline $\begin{array}{c}\text { Colégio Est. Professor } \\
\text { Colares }\end{array}$ & 25 & 46 & 15 & 31 & 37 & 12 & 25 & 9 & 3 & 6 \\
\hline TOTAL & 122 & 207 & 88 & 119 & 154 & 55 & 99 & 53 & 33 & 20 \\
\hline
\end{tabular}

Fonte: Polícia Militar do Paraná - Programa Patrulha Escolar, Ponta Grossa- PR, 2005-2007. Org. Adriane Iaroczinski ${ }^{*} \mathrm{~F}$ - Feminino $\quad$ **M - Masculino

aparecem nas estatísticas da Polícia Militar.

Durante a realização das entrevistas exploratórias com os policiais e representantes dos quatro colégios houve relatos de preocupação com o aumento dos atos violentos cometidos por meninas que, tradicionalmente, não figuravam como autoras. O envolvimento de pessoas do sexo feminino está ligado às rixas, ameaças, lesões corporais e vias de fato. Em geral, há o componente dos ciúmes do namorado ou de amigas na ação violenta. As pessoas do sexo masculino também cometem os mesmos atos verificados para o universo feminino, mas ampliam a tipologia das ações com o porte e uso de drogas e porte de armas brancas. Outro fator que diferencia os universos feminino e masculino são brigas constantes entre os meninos devido às rixas antigas oriundas do espaço externo à escola que acabam por deflagrar conflitos no espaço escolar.

As pessoas mais diretamente envolvidas na execução do Programa da Patrulha Escolar são os (as) policiais e os (as) diretores (as) das escolas que acabam desenvolvendo uma série de conflitos em relação às suas competências de ação. Além disso, há situações de rompimento das ações do programa devido às divergências de ambos os campos de atuação. Tanto a polícia como as administrações escolares concordam que há fatores estruturais para o aumento da violência escolar envolvendo crianças e adolescentes. Apontam para a desestruturação familiar, precárias condições econômicas, falta de limites e ausência por parte dos pais. Por extensão, as gestões escolares também são criticadas por não desenvolverem ações mais rígidas e controladas para coibir os atos violentos dos alunos. Contudo, quando estes mesmos agentes realizaram avaliações do desempenho do programa no cumprimento dos objetivos para diminuição da violência escolar foi apontado, sobretudo, a falta de articulação e desenvolvimento de trabalhos conjuntos entre as escolas, a Patrulha Escolar e a comunidade. Assim, mesmo sabedores dos problemas presentes na operacionalização do programa, ainda não se consegue superar as ações fragmentadas no enfrentamento da violência escolar. O programa possui uma concepção que envolve um trabalho em redes de atores e uma visão ampla das relações entre o espaço escolar e o espaço urbano, mas, o que tem se desenvolvido são ações isoladas e de pequena efetividade, acarretando um quadro de frustrações entre os profissionais envolvidos. 


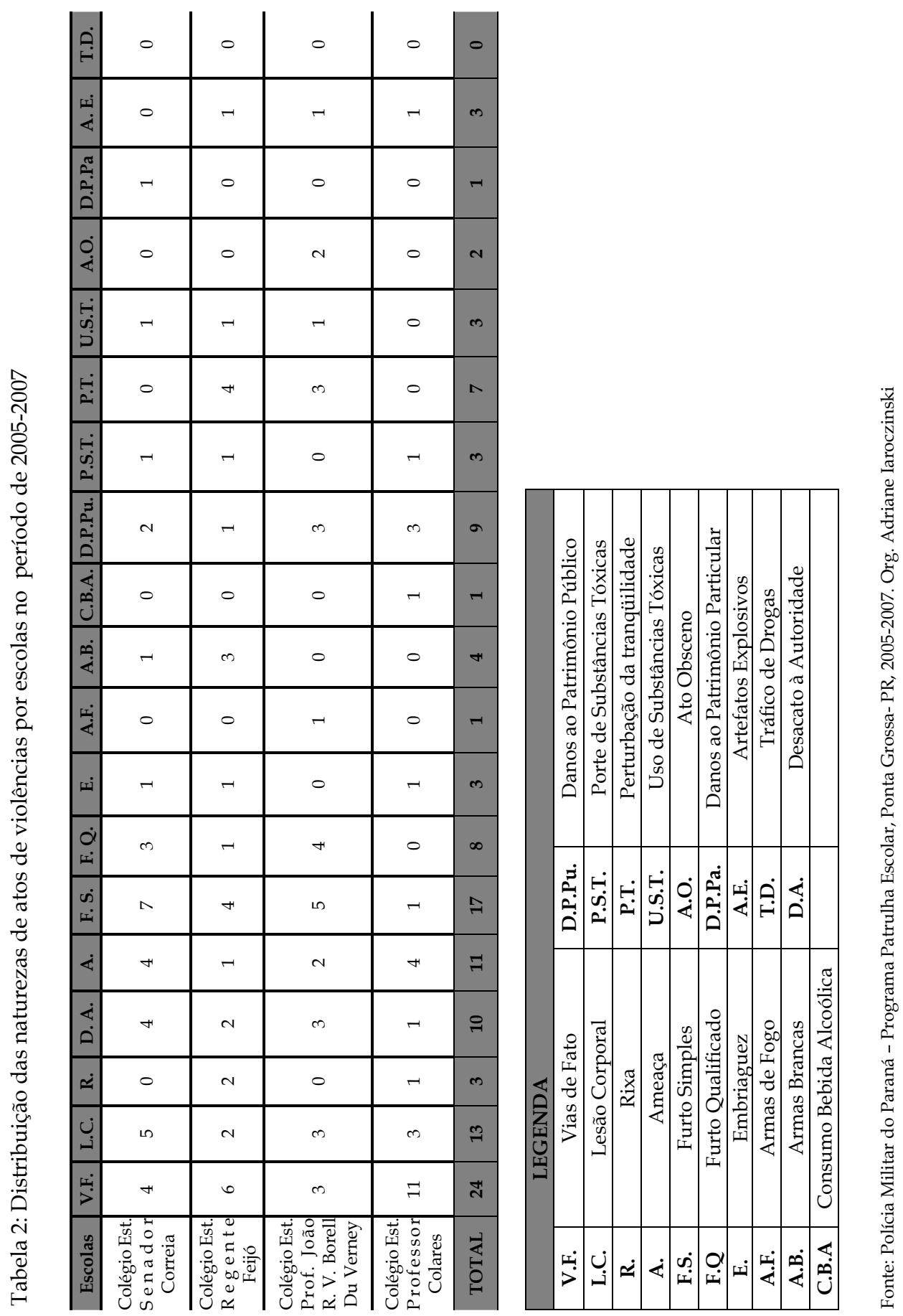


ESPaÇO ESCOLAR E VIOLÊNCIA NO COTIDIANO VIVIDO POR CRIANÇAS E ADOLESCENTES EM PONTA GROSSA- PR ...

\section{CONSIDERAÇÕES FINAIS}

As escolas contemporâneas são ambientes tensos, compostos por uma população fortemente heterogênea em diversos sentidos, tanto no que diz respeito ao perfil de renda e faixa etária, como dos valores sociais e morais, conforme apontam Alves e Pretto (1999). A complexidade que estrutura o espaço escolar tem sido negligenciada e a escola tem reproduzido os mesmos elementos presentes no espaço urbano como um todo como a exclusão, a repressão e a submissão. A análise dos dados coletados para esta pesquisa demonstrou que durante o período de 2005 a 2007 os indicadores da violência infanto-juvenil presentes nas instituições de ensino público na cidade de Ponta Grossa-PR continuam constantes. A violência escolar, apesar do Programa da Patrulha Escolar estar presente e atuante, ainda continua sendo um importante desafio da sociedade urbana. Contudo, é necessário que haja a superação da visão da escola como instituição isolada. $\mathrm{O}$ espaço escolar é criação social, instituído pela sociedade que lhe dá sentido e ao mesmo tempo, dela instituinte. A partir dessa concepção pode-se imaginar a escola enquanto movimento constante de transformação social e sendo assim, ela pode constituir-se em espaço de resistência e contribuir para uma cidade mais solidária e pacífica.

\section{REFERÊNCIAS BIBLIOGRÁFICAS}

ABRAMOVAY, Miriam. Escola e violência. Brasília: UNESCO, 2002.

ALVES, Lynn Rosalina Gama; PRETTO, Nelson. Escola: um espaço de aprendizagem sem prazer. Revista Comunicação \& Educação, n.16 p.29-35, set/dez. 1999. Disponível em: $<$ http://www2.ufba.br/ pretto/textos/crian- cas.htm>. Acesso em 31 jul. 2007.

AQUINO, Julio Groppa (Org.). Diferenças e preconceito na escola: alternativas teóricas e práticas. São Paulo: Sammus, 1998.

CORRÊA, Roberto Lobato. Trajetórias geográficas. Rio de Janeiro: Bertrand Brasil, 1997.

ECA - Estatuto da Criança e do Adolescente. Ponta Grossa: CMDCA, 2006.113 p.

FERNÁNDEZ, Isabel. Prevenção da violência e solução de conflitos: o clima escolar como fator de qualidade. São Paulo: Madras, 2005.

FRANCO, Luiz Antonio de Carvalho. A escola do trabalho e o trabalho da escola. São Paulo: Cortez, 1987.

GANDIN Danilo. Escola e transformação social. Rio de Janeiro: Vozes, 1997.

GETE - GRUPO DE ESTUDOS TERRITORIAS.

MOCHCOVITCH, Luna Galano. Gramsci e a escola. São Paulo: Ática, 1990.

OLIVEIRA, Antunes de Betty; DUARTE, Newton. Socialização do saber escolar. São Paulo: Cortez, 1986.

PARANÁ, Secretaria de Estado da Educação. Núcleo Regional de Educação de Ponta Grossa.

PARANÁ, Polícia Militar. Programa Patrulha Escolar.

PREFEITURA MUNICIPAL DE PONTA GROSSA.

SANTOS, Milton. A natureza do espaço: técnica e tempo. razão e emoção. São Paulo: Hucitec, 1996.

SAVIANI, Dermeval. Escola e democracia. São Paulo: Cortez, 1991.

SOJA, Edward Willian. Geografias pós-modernas: a reafirmação do espaço na teoria social crítica. Rio de Janeiro: Jorge Zahar, 1993.

(Recebido em 27/12/2007 e aceito para publicação em 11/05/2008) 